\title{
PERCEPTION OF PUBLIC E-SERVICES BY RUSSIAN CITIZENS: A PILOT STUDY IN ST.PETERSBURG
}

\author{
A. A. GOLUBEVA, E. V. GILENKO \\ Graduate School of Management, St.Petersburg State University, Russia
}

\begin{abstract}
The paper explores some issues of public e-services perception by Russian citizens. Based on the modern literature, we construct a hierarchical model of public e-services (PeS) adoption. We argue that the coexistence of public services provision in the traditional format with electronic one represents the nowadays specifics of PeS adoption in Russia. Thus PeS is actually not an integral part of the public services delivery process. The research is based on the authors' survey of the St. Petersburg Portal of Public Services and up-to-date techniques of data analysis. We demonstrate that the Russian customers of public e-services indeed do not perceive as a part of the integral process of public services provision. The article concludes with special recommendations on further PeS delivery process development and improvement.
\end{abstract}

Keywords: public e-services, e-government, citizens' attitudes, factor analysis, cluster analysis.

JEL: H11, H41, H70.

Development of information and communication technologies (ICT) at the end of the 20th century and the beginning of the 21st century allowed state authorities to expand their approaches to improving organizational models and methods for interaction with the customers of public services. The private sector's success in the development of new, more effective and client-oriented ICT-based business models inspired governments worldwide to develop their own e-government concept.
The rapid growth of speed and quality of information transfer, the development of e-commerce and social networks over the last ten years have radically changed the methods and means of communication of citizens with organizations and with each other. As a consequence, citizens' expectations regarding the availability and quality of public services have been increasingly associated with simplification of access to such services - from any point, all over the globe, and at any time, using different communication channels.

Postal Address: 3 Volkhovskiy per., Graduate School of Management, St.Petersburg State University, St.Petersburg, 199004, Russian Federation

(C) A. A. Golubeva, E. V. Gilenko

DOI: $10.21638 / 11701 /$ spbu18.2017.302 
Today, e-government development strategies are aimed at providing greater personalization of citizen service through multichannel access to public services, which practically means combination of the traditional and electronic forms of interaction. Thus, in reality, the traditional and electronic channels coexist and complement each other, requiring effective coordination of the supply and demand side of public services. Any government has various expectations associated with the customer self-service promotion, like marginal cost reduction, lower bureaucracy, better customer satisfaction and greater overall confidence and trust in the government. Therefore, public services demand studies are crucial for better understanding of the customers and creation of channels mix, adequate to the current customer preferences.

Although there are many studies focused on the public e-services (PeS) supply and technology issues, still there is a lack of research that examine the citizens' demand for and the use of PeS [Gould, Goldfinch, Horsburgh, 2010]. Nevertheless, a low level of PeS adoption by citizens represents one of the main limiting factors of the return on investment in different e-government projects around the world [Hung, Chang, Yu, 2006]. Evidence from countries - the leaders of e-government development (like Australia, the USA, the UK) - reveals that individuals not simply use the new ICT in different and sometimes unexpected ways, but also may actively resist the use of them [Fountain, 2001]. The neglect of demand studies leads to low efficiency and effectiveness of public e-services, undermines citizens' trust in the new ways of interaction with public authorities, limits the customer orientation to the newly created PeS.

There are several important reasons to conduct a deeper PeS demand-side research in Russia and shed light on the peculiarities of Russian customers attitudes towards public e-services. First, Russia has made a significant leap in the e-government development. According to the UN e-government survey of 2016, by the level of online services development Russia has improved its position from the 50th in 2005 to the 35 th in 2016 out of 193 countries [UN, 2016]. Since the early 2000s, a number of federal programs and concepts have been implemented, such as "Electronic Russia 2002-2010", "The Concept of e-government development till 2010", "Information society 2011-2020". Up to now, the regional governments have implemented interagency electronic systems, multifunctional centers for public services delivery, regional public services web-portals, etc. For the federal PeS provision, the Uniform Federal portal was created. As statistics show, the most popular e-services among the citizens of Russia are doctor appointments, traffic fines information, filing of tax returns, issue of foreign passports, registration at the place of residence, issue and change of national passports [Minsvyaz, 2015].

Second, despite numerous studies focused on the assessment of public e-services development, there has been little evidence on the public e-services customer profiles, particularly, as far as the customer peculiarities or behavioral characteristics are concerned. The demand-side research has usually been limited to the overall descriptive statistics on a number of public e-services customers and their preferences towards the proposed PeS [InfoCity, 2014]).

Third, significant budget constraints of the last several years require a much more balanced policy for the public e-services development, including demand stimulation programs, for providing a higher return on investments. Such programs should be based on detailed customer studies allowing effective customer segmentation and targeting.

Fourth, according to the Decree of the President of the Russian Federation of 07.05.2012 No.601 “On Main Directions of Improving the System of Public Administration" $70 \%$ of citizens must use electronic public services by 2018. This task leads to additional pressure on the public authorities, responsible for public e-services development, and strengthens the need for the demand research.

PЖM 15 (3): 289-302 (2017) 
In this paper we put forward a simple model of PeS adoption by citizens. As we discuss below, this model is relevant to the current situation with $\mathrm{PeS}$ adoption in Russia as there is, virtually, no research on the attitudes of Russian citizens towards PeS.

In an attempt to fulfill the lack of such research, we carried out a pilot study on customers of PeS in St. Petersburg which is the second largest city in Russia in terms of population and is one of the leaders on the ICT and e-government development [Minsvyaz, 2016]. The regional web-portal of public e-services in St. Petersburg provides more than 150 public services in the electronic form. Nevertheless, the overall demand for these public e-services remains comparatively low. According to the official statistics, the fraction of the St.Petersburg citizens that used public e-services in 2016 was $49 \%$ which is even less than Russia's average of $51,3 \%$ [Rosstat, 2017].

Thus, the aim of this research is to reveal the St.Petersburg citizens attitudes towards the public e-services as provided via the St. Petersburg Web-Portal of Public Services (hereafter, Portal). We limited the scope of our research to a pilot study, which allows to preliminary answer the principal questions on PeS adoption by Russian citizens in a general way and to clarify the requirements for a further bigger research.

The rest of the paper is organized as follows. Section 1 provides literature review on the topic. In section 2 we discuss the theoretical framework of the research, as well as give the description of the research methodology and the collected sample. Section 3 is devoted to discussion of the obtained results. Section 5 contains recommendations and concludes.

\section{Literature review}

Studies of the demand for public e-services often imply assessment of how and why consumers adopt these services or refuse to use them [Reddick, 2005]. In a general form, the demand for PeS is studied in the following three principal ways [Golubeva, Merkuryeva, 2006].

1. Research on the citizens' awareness. Such papers focus on the analysis of the degree of public awareness about various e-government programs and projects or the analysis of the existing range of public services, available in the electronic format (see, for example, [Choudrie, Dwivedi, 2005; Al-Jaghoub, Al-Yaseen, AlHourani, 2010]).

2. Research on the usage intensity. Within this group of studies a particular importance is attached to assessment of the level of PeS demand, based on the degree of users' activity. In this type of studies, the structure of the already existing demand is revealed. The assessment of the current and potential usage intensity allows to understand which e-Public services need to be supported and developed [Nam, 2012].

3. Studies on the factors of demand. In these studies, the main purpose of research is to reveal the factors affecting the demand for public e-services. This strand of literature includes studying of the user satisfaction with the existing PeS and identification of the factors limiting the use of these services (see, for example, [Carter, Bélanger, 2005; Gould, Goldfinch, Horsburgh, 2010; Niehaves, Gorbacheva, Plattfaut, 2013; Taipale, 2013; Öktem, Demirhan, Demirhan, 2014; Hamid et al., 2016]).

This last group of studies represents the major interest for our research. We referred to the previous studies in different countries in order to create a list of the most important PeS demand factors, which were revealed by other researchers. As our analysis showed, these factors are related to access to, trust in, and motivation for usage of electronic channels of interaction with the government.

\subsection{Access to public e-services}

Access to the electronic channels of communication with the government directly affects the level of social involvement as 
a result of the implementation of the relevant projects. The citizens' access to PeS should be considered from two principal angles: (1) as access to the communication technology (Internet) and (2) as a possibility of multi-channel access to PeS.

1. The group of factors (customers' characteristics) such as availability of physical access to the Internet, digital literacy and Internet usage experience, educational level of the user, etc., are of crucial importance when the government chooses optimal channels of interaction to improve the delivery of its e-services. For instance, research on the factors influencing the usage of PeS in Turkey in 2014 revealed the significance of the Internet access for public e-services adoption [Öktem, Demirhan, Demirhan, 2014]. A similar research for Australia and New Zealand in 2010 confirmed the important role of the Internet usage experience [Gould, Goldfinch, Horsburgh, 2010].

2. However, provision of physical access to the electronic format of PeS delivery is majorly not enough. To construct a comprehensive organizational model for the provision of public services, comprising a set of channels of interaction, the multi-channel public service delivery is of principal importance. Specifically, customers of PeS should have several options of obtaining a PeS, including a web-portal access, a special application, an electronic kiosk, etc.

Under a multi-channel public service delivery framework, the customer independently chooses a channel from the offered ones, guided by the criteria of accessibility, convenience, personal preferences or circumstances, and the provider implements the strategy of multichannel provision of public services - an action plan aimed at optimizing the processes of providing public services through developing a complex of interrelated traditional and new channels of interaction.

Thus, development and implementation of a customer-oriented strategy for the de- velopment of multi-channel access to public services requires that the executive authorities make informed choices about new channels of interaction, taking into account the factors influencing such choice.

For example, it has long been discussed that in the implementation of public services for target groups with a low level of digital literacy, the preferred channels for interaction will be multifunctional centers of consumer service or electronic kiosks. A study, conducted in Germany in 2013 and based on a sample of 1930 respondents from three major cities, proved, in particular, the significance of the user's education level for public e-services adoption [Niehaves, Gorbacheva, Plattfaut, 2013]. Another research, conducted in Finland in 2013, revealed that not only the level of education, but also the level of income, family structure, as well as the size of the city could predict the level of public e-services use [Taipale, 2013].

Thus, the accessibility of ICTs in general and the level of users' access to new ICTs (defined as their ability to use ICT for receiving electronic services) are basic conditions for formation of demand for public e-services.

\subsection{Trust in the electronic communication with authorities}

Once access to PeS is duly provided, customers' trust in interaction with authorities in the electronic format comes to front. And this trust is determined by two principal aspects - technological and institutional. Various studies showed the importance of trust, both in the new technologies and in the government at large, in increasing the usage of the new channels of interaction (see [Warkentin et al., 2002; Welch, Hinnant, Moon, 2005; Colesca, 2009; Lamberti, Benedetti, Chen, 2014]).

Technologically speaking, the trust in electronic channels of communication largely depends on the user's previous experience and their belief in reliability and security of such communication. So, when ensuring appropriate measures to protect infor- 
mation and data sent over such channels, trust in electronic transactions increases over time. The research, conducted among the local population of the United States in 2005 , showed that both public trust in the government and confidence in the Internet explain the intention of citizens to use public services in the electronic form [Carter, Bélanger, 2005].

But it is much more difficult to change the level of institutional trust and the established stereotypes of interaction with authorities. By exerting a significant influence on the demand for PeS, the level of confidence in the government itself becomes a crucial factor in the success of PeS adoption.

The traditions of relations between the state and the society may weaken the incentives for switching from the traditional to the electronic channels of interaction, since both parties, involved in the process, lose the opportunity of personal influence on the process of PeS provision/obtaining. Studies show that individuals are more likely to use the electronic format only to obtain the necessary information rather than to completely solve specific problems by receiving the corresponding public's services. In addition, in several studies, the perceived quality of traditional channels was shown to be correlated with the adoption of the new electronic channels of interaction, that is, increasing the quality of service within the traditional channels increases the demand for the new electronic channels (see [Lee, Kim, Ahn, 2011]). For example, a study conducted in Canada in 2012 showed that citizens who had previous positive experience of the traditional interaction with the authorities were late three times more satisfied with the usage of PeS [Reddick, Turner, 2012].

Thus, users' trust in public electronic services and their willingness to use them directly depends on the users' previous experience in electronic interaction (making transactions), and on their experience in off-line interaction with public authorities. Therefore, the users' level of trust based on that experience creates the next principal condition, positively affecting the attitudes towards public e-services and their adoption.

\subsection{Motivation for using public e-services}

The motivation for using the new electronic channels of interaction is determined by the expected benefits from their use, which are related, first of all, to the qualitative characteristics of these new channels, as well as the number of services that the user can receive with their help. For example, a research on the public e-services usage, conducted in Malaysia in 2016, proved a significant role of the perceived benefits in the PeS demand formation. The authors found that the perceived usefulness and the ease of use are strongly positively correlated with the intention of citizens to use PeS [Hamid et al., 2016].

And this should be a starting point for changing the proportion of users of the traditional and the electronic channels of obtaining public services. The key thing here is that the new electronic channels of interaction provide lower unit cost of a service. Therefore, the distribution of customers between the traditional and the electronic channels is crucially important for minimizing the aggregate costs of serving citizens.

In this regard, public authorities in the advanced economies develop different channel migration strategies, encouraging customer self-service. The success of these strategies largely depends on the customers' attitudes to the electronic channels of interaction (via the public services portals, for example) and their willingness to receive services in this new format.

In a number of Western countries, whole systems of special incentives for customers are used, which allow to provide additional benefits through the use of electronic channels, e.g. submission of documents in the electronic form; free software and training programs; additional services of automatic calculation of taxes, provision of free certified electronic copies of documents, notifications in electronic format, etc. In some countries, 


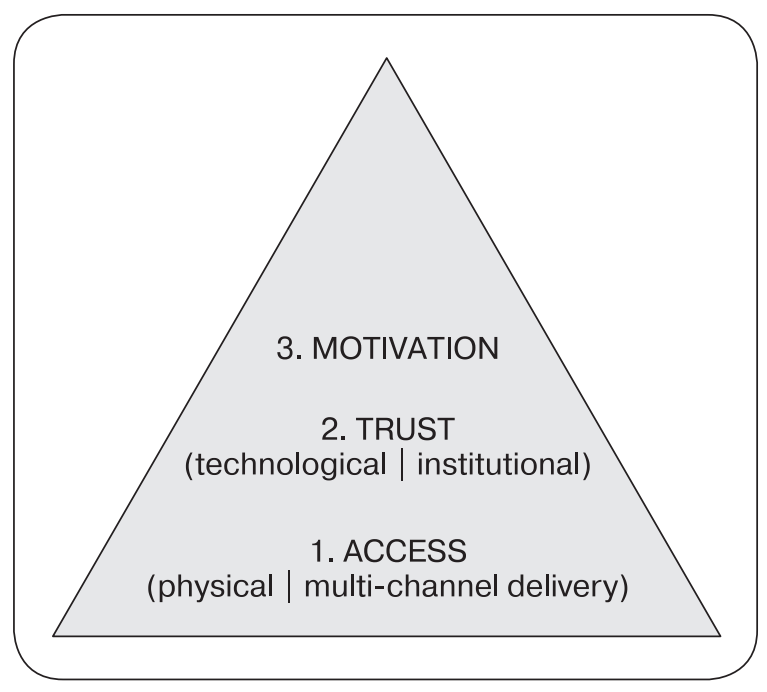

Fig. 1. Hierarchical model of public e-services adoption

the electronic format of interaction with the government when filing tax returns is specified in the legislation, f.e. in Australia, the electronic format is required to use by organizations with the annual turnover of more than 20 million USD, in Austria - more than 100,000 euros [OECD, 2016].

It is also important to emphasize that the perceived quality of the proposed e-government services is one of the main motivating factors for their use. It can be determined by the ease of use, the speed of service provision, usability, as well as other benefits. This conclusion was made in a research of Italian authors where they showed that the new electronic channels of interaction were more positively perceived by users, if the quality and security of electronic services was at least not lower than that of their traditional counterparts [Lamberti, Benedetti, Chen, 2014].

Thus, access and trust are the necessary conditions for formation of a positive attitude towards public electronic services, but they are definitely not enough to make the consumers become loyal to PeS. Motivation, caused by the perceived quality of public eservices, is the next principal piece in the chain of formation of the loyal attitude [Lindgren, Jansson, 2013].

\section{Research methodology}

The three above-discussed aspects related to PeS adoption by citizens constitute the theoretical framework for the current research. In this section we discuss this framework as well as describe the empirical methodology.

\subsection{Research background}

In our opinion, the above-specified aspects of $\mathrm{PeS}$ adoption (access, trust, and motivation) should be considered as consecutive components of a hierarchical model of PeS adoption, where on the first level it is important to provide access to $\mathrm{PeS}$, then, on the second level, to support trust in PeS, and on the third level to appropriately motivate the customers to use PeS (see fig. 1). Only when all three conditions are met, the government can substantially increase the level of PeS adoption by its citizens.

Let us now discuss how this model relates to the current situation with $\mathrm{PeS}$ adoption in Russia, because on each of the levels there are certain peculiarities for its citizens.

Level 1. Access. PeS adoption on this level is majorly not of a big problem in modern Russia, specifically, in big cities. According to a recent study of the "Public Opinion" Fund, the average level of Internet usage by people in big cities (with population of more than 1 million people) is $73 \%$ as of the early 2017, while as of fall 2016 it was $71 \%$. For St. Petersburg, these numbers are 83 and $79 \%$, correspondingly. So, we can see that most of the population in Russia has physical access to the Internet [FOM, 2017].

As for the opportunities of multi-channel delivery of access to PeS, out of the $71 \%$ of total Russian population who have access to the Internet, $16 \%$ use only mobile devices, less than $1 \%$ use only personal desktop PCs, and $54 \%$ use both [Mediascope, 2017].

So, as of today, with quite a wide-spread access of the people to the Internet from both the desktop and mobile devices, public e-services can indeed be provided via different channels. 
Level 2. Trust. On this level, trust in the modern technologies is not a problem for the Russian citizens. According to Rosstat, the share of population, not using the Internet due to security reasons, was only $0,5 \%$ of the total population in 2016, while in 2014 it was $2,2 \%$ [Rosstat, 2017]. So, usage of new electronic technologies for public services delivery should not be a barrier for PeS adoption.

The actual barrier to a wide-spread PeS adoption in Russia arises within the institutional aspect of trust. Unlike public services in the traditional format, nowadays in Russia public electronic services usually cover only a part of the whole service delivery process. In the majority of cases, the applicant can only submit the application and the necessary documents electronically. But in order to receive the result of a public service, he or she still has to visit the corresponding state body. For a very limited number of public services, the whole process of obtaining such services is completely in the electronic format.

Another important barrier is that a lot of processes of public services delivery in Russia are non-transparent to the Russian citizens. All this forces them to choose the traditional format (say, personal visit to a multifunctional center) more often, because, in this case, the applicant will at least be sure that he or she indeed submitted the correct package of documents and filled out the necessary forms correctly. Thus, the confidence (trust) in the ability to correctly go through the whole PeS delivery process personally and distantly is undermined.

Level 3. Motivation. Unfortunately, the problems on the level of institutional trust virtually do not allow a full-fledged motivation for citizens to switch to PeS. Once the applicant has to use a combination of traditional and electronic channels of PeS delivery, the integrity of the whole process of interaction with the e-government will break.

Thus, despite the obvious benefits of transferring even a part of the process to the electronic format, the customer, as a consequence, does not distinguish between the service channels and prefers the one with less risk of not obtaining the public service at all.

These considerations get us to the main research hypothesis.

Hypothesis. Nowadays, Russian citizens do not perceive public services delivery in the electronic format as an integral part of the whole public services delivery process.

This hypothesis is tested below on an illustrative sample of citizens of St.Petersburg who used the St. Petersburg Portal of Public Services.

\subsection{Sample collection}

To reach the aim of this research and test the main research hypothesis, we developed our own questionnaire and ran a survey among 56 randomly chosen St. Petersburg citizens who:

- was able to access to the Internet (at home/ at work/from a personal mobile device);

- were aware of the Portal and the public services it was providing;

- had previous experience in obtaining public services online in general and via the Portal specifically.

The survey was run in May 2016. The answers were collected by asking people in person. The questionnaire consisted of the following parts:

- Part 1: a sub-questionnaire on socio-demographic characteristics of the citizens (such as age, gender, level of income, access to the Internet, readiness to make transactions via the Internet);

- Part 2: a sub-questionnaire on the quality and attitude towards the Public services in general and those provided via the Portal (in the electronic format) in particular.

Taking into account the fact that all the respondents have all the above-mentioned characteristics, we can state that they pass the first (basic) level of the public e-services adoption model described in section 3 . This is why Part 2 of the questionnaire contains direct questions on the citizens' attitudes towards trust and quality of public services both in the traditional and the electronic formats. 
Table 1

Description and mean values of the variables

\begin{tabular}{|c|c|c|c|}
\hline Variable & Description & Type and range & \begin{tabular}{|c|} 
Mean \\
value $^{+}$
\end{tabular} \\
\hline \multicolumn{4}{|c|}{ Part 1. Characteristics of the respondents } \\
\hline gender & Respondent's gender & Binary $(1-$ male, 0 - female $)$ & 0,27 \\
\hline age & Respondent's age (full years) & Integer & 32,1 \\
\hline education & Respondent's level of education & $\begin{array}{l}\text { Integer. } \\
5 \text {-point Likert scale }(1-\text { incomplete sec- } \\
\text { ondary education; } 2-\text { complete secondary } \\
\text { education; } 3-\text { complete secondary special- } \\
\text { ized education; } 4-\text { higher education; } 5- \\
\text { scientific degree) }\end{array}$ & 3,91 \\
\hline $\begin{array}{l}\text { marital } \\
\text { status }\end{array}$ & Marital status of the respondent & $\begin{array}{l}\text { Binary }(1-\text { married/lives with a partner; } \\
0-\text { divorced/lives alone })\end{array}$ & 0,86 \\
\hline children & Whether the respondent has children & Binary $(1-$ yes, $0-$ no $)$ & 0,54 \\
\hline income & The level of income of the respondent & $\begin{array}{l}\text { Integer. } \\
5 \text {-point Likert scale }(1-\text { low; } 2-\text { below } \\
\text { average; } 3-\text { average; } 4-\text { above average; } \\
5-\text { high })\end{array}$ & 3,3 \\
\hline readiness & $\begin{array}{l}\text { Readiness to make financial transac- } \\
\text { tions on the Internet }\end{array}$ & Binary $(1-$ yes, $0-$ no $)$ & 0,82 \\
\hline intention & $\begin{array}{l}\text { Intention to use the Portal in the } \\
\text { future }\end{array}$ & Binary $(1-$ yes, $0-$ no $)$ & 0,79 \\
\hline \multicolumn{4}{|c|}{ Part 2. Attitude variables } \\
\hline trust & Trust in the public services in general & \multirow{5}{*}{$\begin{array}{l}\text { Integer. } \\
5 \text {-point Likert scale }(1-\text { highly negative, } \\
5-\text { highly positive })\end{array}$} & 2,8 \\
\hline qualtradserv & $\begin{array}{l}\text { Quality of the traditional (non-elec- } \\
\text { tronic) public services provision }\end{array}$ & & 3,0 \\
\hline qualonline & $\begin{array}{l}\text { Quality of online public e-services in } \\
\text { general }\end{array}$ & & 3,7 \\
\hline qualportal & $\begin{array}{l}\text { Quality of online public e-services } \\
\text { obtained specifically via the Portal }\end{array}$ & & 3,5 \\
\hline convenience & $\begin{array}{l}\text { convenience of obtaining online pub- } \\
\text { lic e-services via the Portal }\end{array}$ & & 3,5 \\
\hline
\end{tabular}

Note: ${ }^{+}$- The mean values for categorical variables are calculated to provide additional information about the sample structure. Mean values of the binary variables show the fractions of categories coded as 1 . Mean values for the Likert scales are given to show the average level of the corresponding attribute in the sample.

The description of the variables used in the research is given in table 1 .

\subsection{Empirical methodology}

Methodologically, the following procedures were conducted $^{1}$.

1 The details of the used techniques (exploratory factor analysis and hierarchical cluster analysis) can be found, for example, in [James et al., 2017]. The calculations were made in statistical package $R$ version 3.3.2.
Step 1. After analyzing the reliability of Part 2 of the survey (using the Cronbach's alpha), an exploratory factor analysis (EFA) on the corresponding 5 variables was run to reveal the latent structure of citizens' attitudes toward public services (both traditional and electronic).

Numerically, EFA allows to do at least two important things. First, reduce the number of the original variables by recombining them into a fewer number of factors and 
Table 2

EFA: factor loadings and eigenvalues

\begin{tabular}{l|c|c}
\hline \multicolumn{1}{c|}{ Variable } & $\begin{array}{c}\text { Factor 1. } \\
\text { Portal loyalty }\end{array}$ & $\begin{array}{c}\text { Factor 2. } \\
\text { Public service loyalty }\end{array}$ \\
\hline qualonline & $\mathbf{0 , 7 8}$ & 0,12 \\
\hline qualportal & $\mathbf{0 , 9 9}$ & 0,01 \\
\hline convenience & $\mathbf{0 , 6 2}$ & 0,17 \\
\hline qualtradserv & 0,25 & $\mathbf{0 , 7 4}$ \\
\hline trust & 0,01 & $\mathbf{0 , 5 4}$ \\
\hline \multicolumn{1}{c|}{ eigenvalue } & 2,05 & 0,79 \\
\hline
\end{tabular}

Note: The total variance explained by the two factors is $\sim 0,74$. The test of the hypothesis that two factors are sufficient has the chi-square statistic of 0,92 with the $p$-value of 0,337 meaning non-rejection of the null. Given in bold are the loadings higher than 0,5.

filtering out the noise information. Second, give new informative interpretations to the obtained factors.

Step 2. Using the obtained by EFA factors, a hierarchical cluster analysis was run on these factors in order to detect and describe specific groups by the loyalty to public services (as well as to control for possible heterogeneity even despite 2 the moderate sample size of 56 observations).

\section{Discussion of the empirical results}

\subsection{The citizens' attitude towards public services}

As it was mentioned before, to check the validity of the questionnaire on the quality of the Public services, the Cronbach's alpha was calculated and found to be equal $\sim 0,7$ which speaks in favor of an acceptable quality of Part 2 of the questionnaire (the generally agreed upon lower limit for Cronbach's alpha is 0,70 [Nunnaly, 1978]).

To increase the interpretability of the outcomes of the Public service quality questionnaire, an exploratory factor analysis was conducted to identify the structure of the citizens' attitudes in a more detailed manner. The results are provided in table 2 and in fig. 2 .

Fig. 2 is known in factor analysis as biplot which is a type of exploratory graph constructed, particularly, to depict the original variables in the coordinates of new factors (the first two principal component) and to see which of them are closely correlated. Table 2 presents the loadings of the original variables in the newly constructed factors. Original variables with loadings exceeding the threshold 0,5 value were selected for inclusion in the new factors.

As it can be seen from table 2 and fig. 2, the five variables can actually be combined into 2 principal factors (Factor 1 and Factor 2) which, according to their components, seem reasonable to be named, correspondingly, Portal loyalty and Public service loyalty. In fig. 2 these two factors are schematically shown with two dashed arrows.

The non-triviality of this finding lie in the fact that the original five variables form these specific groups. For example, surprisingly, but neither estimate of trust, nor estimate of the quality of traditional public services are not correlated with the variables associated with the Portal. The combinations of the corresponding variables (depicted as the dashed arrows in fig.1) are orthogonal to each other.

Basically, this means that the citizens perceive the Portal (electronic) public services and the traditional public services as independent of each other. This finding speaks in favor of our main research hypothesis: unfortunately, the surveyed citizens do not perceive public e-services as an integral part of public services in general.

Specifically, for the Portal authorities this means the following: unfortunately, as 


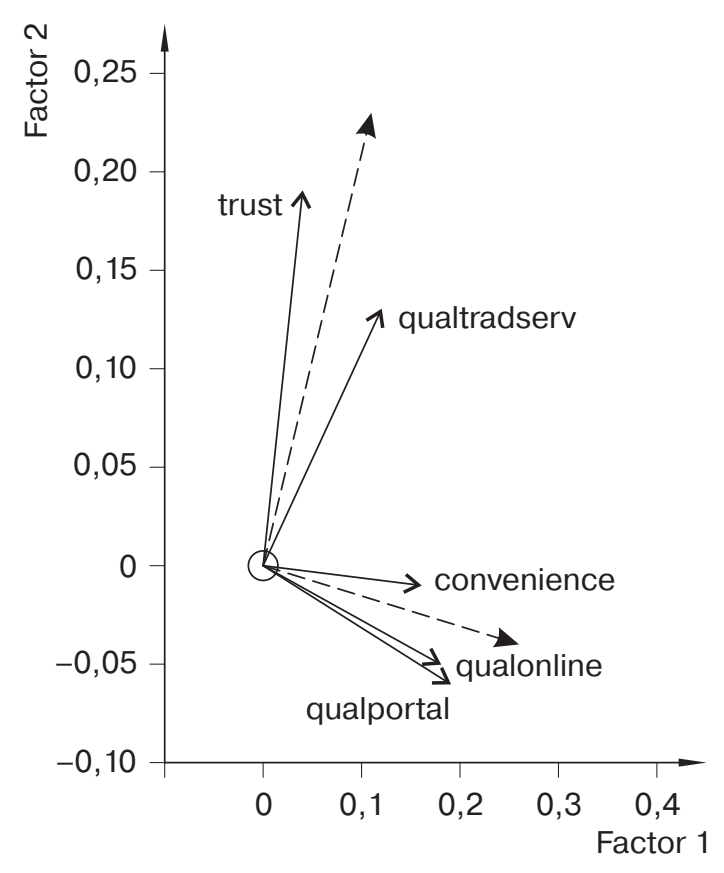

Fig.2. Graphical representation of the results of the EFA

of nowadays, the efforts of the authorities make to increase popularity of the Portal e-services would not be backed up by the trust of the citizens in the public services in general. Thus, the proclaimed popularization of public e-services may encounter additional difficulties.

\subsection{Portraits of typical public e-service customers}

At the second step of our analysis, we used the two obtained factors to run a hierarchical cluster analysis (HCA) to take a closer look at the characteristics of the citizens according to their attitude both towards the traditional and the public e-services. This allowed us to construct several typical portraits of the St.Petersburg PeS customers.

Using the Ward linkage method, we ran HCA and applied the Hartigan pseudo $F$-index [Hartigan, 1975] to find the optimal number of clusters which occurred to be four. The mean values of all the socio-demographic variables and the previously calcu- lated Factor 1 and Factor 2 are given in table 3 for each of the clusters (groups).

The mean values of the loyalty factors are of primary interest for us in this segmentation. Mathematically, the positive sign means that the group (cluster of citizens) is indeed loyal in the corresponding aspect, while the negative sign means the opposite. The obtained results suggest that we have identified all four possible combinations of the citizens' attitudes towards public services both in the traditional and the electronic forms.

Group 1. Citizens of that group have negative loyalty to the Portal, but positive loyalty to the traditional public services. Appoximately, only the half of these people $(55 \%)$ intends to use the Portal in the future. They are quite young (average age is 29 years) and well-educated (average education is 4,1 ) people, who are not afraid to run transactions on the Internet (average readiness is $100 \%$ ).

The possible disloyalty to the Portal services may stem from their higher require- 
Table 3

Cluster profiles (mean values of the variables)

\begin{tabular}{l|c|c|c|c}
\hline \multicolumn{1}{c|}{ Variable } & Group 1 & Group 2 & Group 3 & Group 4 \\
\hline gender & 0,27 & 0,25 & 0,22 & 0,36 \\
\hline age & 29,1 & 36,4 & 30,3 & 31,7 \\
\hline education & 4,1 & 3,9 & 3,8 & 3,9 \\
\hline marital status & 0,91 & 0,81 & 0,78 & 1,00 \\
\hline children & 0,64 & 0,50 & 0,39 & 0,73 \\
\hline income & 3,5 & 3,1 & 3,3 & 3,4 \\
\hline readiness & 1,00 & 0,63 & 0,94 & 0,73 \\
\hline intention & 0,55 & 0,94 & 1,00 & 0,46 \\
\hline Portal loyalty (Factor 1) & $-0,89$ & 0,49 & 1,49 & $-2,28$ \\
\hline Public service loyalty (Factor 2) & 0,94 & $-1,22$ & 0,69 & $-0,31$ \\
\hline Group size & 11 & 16 & 18 & 11 \\
\hline \% of the sample & 19,6 & 28,6 & 32,2 & 19,6 \\
\hline
\end{tabular}

$\mathrm{N}$ ot e: Mean values of binary variables are the fractions of ones.

ments to the quality of provision of the Portal services. Therefore, the Portal authorities should work hard at improvement of the e-services provision quality to attract such citizens to use the Portal.

Group 2. These citizens are older (average age is higher than 36 years), though, also well-educated (average education is 3,9 ), but only $63 \%$ of them are ready to actively make transactions on the Internet, the latter value being the smallest across all the four groups. These people are not loyal to the traditional Public services, but loyal to the Portal $-94 \%$ of them are ready to use the Portal in the future. Due to their age, they may already have negative experience with the traditional services, thus, disloyal to them, but have hopes about the new electronic technologies and, thus, are loyal to the Portal.

This means that the Portal authorities should use the loyalty of this group of citizens and make all the necessary efforts to persuade them in the safety and convenience of working with the Portal.

Group 3. These citizens are loyal to both traditional and electronic Public services. They are young (average age is 30 years) and majorly are not afraid of making transaction over the Internet (average readiness is $94,4 \%$ ). They have a $100 \%$ level of intention to use the Portal in the future.

This means that the Portal authorities should make all the necessary efforts to preserve the loyalty of these citizens and keep them using the public e-services provided via the Portal.

Group 4. The citizens of this group are the most disloyal: the have negative average scores for the both factors. Only $46 \%$ of them intend to use the Portal in the future, preferring personal communication with the government bodies. Although, not very old (average age is 31,7 years), they are not very ready to make transactions over the Internet (only $72,7 \%$ of them are ready to do it). This group has the highest fraction of men $(36,4 \%)$, and all the people of this group are not single.

This is the most difficult group to work with. The authorities should come up with special loyalty programs for such citizens (including different incentives) while actively proclaiming the advantages of the electronic way to obtain public services.

In general, the empirical findings of this research are in line with the current literature and emphasize the following: once the access to PeS is provided (specifically, in the big cities in Russia), there is a strong need for the authorities to work 
on trust and motivation for the citizens to use public services in the electronic format.

\section{Recommendations and conclusions}

In this research the St. Petersburg citizens' attitudes towards public services provision (both traditional and electronic formats) were studied with help of modern statistical methods. The conducted analysis, even despite its pilot nature, allowed us to show that Russian citizens strongly distinguish between the traditional and the electronic forms of public services provision.

Obviously, any government benefits from conversion of public services into the electronic format. First of all, such conversion decreases unit costs of services provision. Second, the electronic form of public services provision allows a much deeper look into the structure of demand for such services and thus, as a result, increases the performance of the provision process.

But transferring public services to the electronic format should be beneficial for both parties - the government and the citizens. Unfortunately, nowadays there is no single

\section{REFERENCES}

Al-Jaghoub S., Al-Yaseen H., Al-Hourani M. 2010. Evaluation of awareness and acceptability of using e-government services in developing countries: The case of Jordan. Electronic Journal Information Systems Evaluation 13 (1): 1-8.

Carter L., Bélanger F. 2005. The utilization of e-government services: Citizen trust, innovation and acceptance factors. Information Systems Journal 15 (1): 5-25.

Choudrie J., Dwivedi Y.K. 2005. Investigating the research approaches for examining technology adoption issues. Journal of Research Practice 1 (1): Article D1.

Colesca S.E. 2009. Understanding trust in e-government. Economics of Engineering Decisions 3: 7-15. strategy for customer migration from traditional to electronic channels of interaction with e-government in Russia. Such strategy for improving the quality of public e-services should:

- cover all the channels through which a service can be provided, thus, unified quality standards are required;

- promote in the value added chain of eservices, meaning that the full process of public service provision should be transferred into the electronic form;

- make transparent the benefits of receiving public services electronically, since these benefits are still not obvious to the customers.

It is important to remember that the modern public e-services in Russia exist along with the traditional ones which provision is inevitable due to the need to ensure social inclusion. Thus, the modern organizational model for public services provision, which involves the use of certain traditional (like counter or telephone) and electronic (like portals, e-kiosks, mobile applications, etc.) channels, means and methods of interaction, should be adequate to the information and communication infrastructure supporting the public services provision.

FOM. 2017. The Internet in Russia: The Dynamics of Penetration. Winter 2016-2017. [Electronic resource]. http://fom.ru/SMIi-internet/13300 (accessed: 25.06.2017). (In Russian)

Fountain J.E. 2001. Building the Virtual State: Information Technology and Institutional Change. Brookings Institution Press: Washington, D.C.

Golubeva A., Merkuryeva I. 2006. Demand for online public services: Case studies from St. Petersburg. International Journal of Government and Democracy in the Information Age 11 (3, 4): 241-254.

Gould R., Goldfinch S., Horsburgh S. 2010. Do they want it? Do they use it? The "Demand-side" of e-government in Australia 
and New Zealand. Government Information Quarterly 27 (2): 177-186.

Hamid A.A., Razak F.Z.A., Bakar A.A., Abdullah W.S.W. 2016. The Effects of Perceived Usefulness and Perceived Ease of Use On Continuance Intention to Use E-government. 7th International Economics \& Business Management Conference (IEBMC 2015); Procedia Economics and Finance, 35: 644-649.

Hartigan J.A. 1975. Clustering Algorithms. Wiley: N.Y.

Hung S.-Y., Chang C.-M., Yu T.-J. 2006. Determinants of user acceptance of the e-government services: The case of online tax filling and payment system. Government Information Quarterly 23 (1): 97-122.

InfoCity. 2014. Annual Report on the Implementation of State Program of Moscow "InfoCity" for The Period 2012-2018 in 2014. [Electronic resource]. http://ig.mos.ru/ about/documents/ (accessed: 25.06.2017). (In Russian)

James G., Witten D., Hastie T., Tibshirani R. 2017. An Introduction to Statistical Learning with Applications in R. Springer.

Lamberti L., Benedetti M., Chen Sh. 2014. Benefits sought by citizens and channel attitudes for multichannel payment services: Evidence from Italy. Government Information Quarterly 31 (4): 596-609.

Lee J., Kim H. J., Ahn M. J. 2011. The willingness of e-government service adoption by business users: The role of offline service quality and trust in technology. Government Information Quarterly 28 (2): 222-230.

Lindgren I., Jansson G. 2013. Electronic services in the public sector: A conceptual framework. Government Information Quarterly 30 (2): 163-172.

Mediascope. 2017. The Number of Internet Users in Russia Reached $87 \mathrm{mln}$ People in 2017. [Electronic resource]. http://mediascope.net/press/news/744498/ (accessed: 25.06.2017). (In Russian)

Minsvyaz. 2015. Share of Citizens, Using E-Public Services Reached Target Value. [Electronic resource]. http://minsvyaz.ru/ en/events/33117/ (accessed: 25.06.2017). (In Russian)
Minsvyaz. 2016. Regional Ranking by the Level of Information Society Development. [Electronic resource]. http://minsvyaz.ru/ $\mathrm{ru} /$ events/35027/ (accessed: 25.06.2017). (In Russian)

Nam T. 2012. Citizens' attitudes toward open government and government 2.0. International Review of Administrative Sciences 78 (2): $346-368$.

Niehaves B., Gorbacheva E., Plattfaut R. 2013. The digital divide vs. the e-government divide: Do socio-demographic variables (still) impact e-government use among onliners. In: Ramón G.-G.J. (ed.). E-Government Success Factors and Measures: Theories, Concepts, and Methodologies. IGI Global; 52-65.

Nunnaly J.C. 1978. Psychometric Theory. McGraw-Hill: N.Y.

OECD. 2016. OECD Comparative Study. Digital Government Strategies For Transforming Public Services In The Welfare Areas. [Electronic resource]. http://www.oecd.org/ gov/digital-government/Digital-Government-Strategies-Welfare-Service.pdf (accessed: 25.06.2017).

Öktem M. K., Demirhan H., Demirhan K. 2014. The usage of e-governance applications by higher education students. Educational Sciences: Theory \& Practice 14 (5): 19251943.

Reddick C.G. 2005. Citizen interaction with e-government: From the streets to servers? Government Information Quarterly 22 (1): 38-57.

Reddick C.G., Turner M. 2012. Channel choice and public service delivery in Canada: Comparing e-government to traditional service delivery. Government Information Quarterly 29 (1): 1-11.

Rosstat. 2017. The Indicators of Development of Information Society in the Russian Federation. [Electronic resource]. http://www. gks.ru/free doc/new site/business/it/monitor_rf.xls (accessed: 25.06.2017). (In Russian)

Taipale S. 2013. The use of e-government services and the Internet: The role of sociodemographic, economic and geographical predictors. Telecommunications Policy 37 (4-5): 413-422. 
UN. 2016. UN E-Government Survey. [Electronic resource]. https://publicadministration.un.org/egovkb/en-us/Reports/ UN-E-Government-Survey-2016 (accessed: 25.06.2017).

Warkentin M., Gefen D., Pavlou P.A., Rose G.M. 2002. Encouraging citizen adoption of e-go- vernment by building trust. Electronic Markets 12 (3): 157-162.

Welch E. W., Hinnant C.C., Moon M. J. 2005. Linking citizen satisfaction with e-government and trust in government. Journal of Public Administration Research and Theory 15 (3): 371-391.

DOI: $10.21638 / 11701 /$ spbu18.2017.302

Initial Submission: June 26, 2017 Final Version Accepted: September 15, 2017

Восприятие электронных государственных услуг российскили гражданали: пилотное исследование в Санкт-Петербурге

\author{
А.А.Голубева, Е.В.Гиленко \\ Институт «Высшая школа менеджмента» СПбГУ, Россия
}

В статье рассматривается проблема восприятия электронных государственных услуг (ЭГУ) российскими гражданами. С учетом современной литературы по этому вопросу мы предлагаем собственную иерархическую модель восприятия ЭГУ, которая легла в основу данного исследования. Отмечается, что особенность российской ситуации с восприятием ЭГУ гражданами на современном этапе заключается в том, что предоставление госуслуг в электронном формате существует одновременно с традиционным форматом их предоставления, причем ЭГУ органично не вписываются в существующий процесс предоставления госуслуг. На основе собственного опроса пользователей Портала госуслуг Санкт-Петербурга и с применением современных методов анализа данных нами продемонстрировано, что российские потребители ЭГУ действительно не воспринимают их как часть общего процесса предоставления госуслуг. Полученные результаты позволили сформулировать ряд рекомендаций для органов государственной власти по дальнейшему развитию процесса предоставления ЭГУ.

Ключевые слова: электронные госуслуги, электронное правительство, отношение граждан, факторный анализ, кластерный анализ.

JEL: H11, H41, H70.

DOI: $10.21638 / 11701 /$ spbu18.2017.302

Статья поступила в редакцию

26 июня 2017 г.

Принята к публикации

15 сентября 2017 г.

PЖM 15 (3): 289-302 (2017) 